diseases $(n=538)$. Considering just the diabetes ICDs, Insulindependent diabetes mellitus (E10) represented 63.6\%, followed by non-insulin-dependent Diabetes (E11) with $24.4 \%$ and unspecified diabetes mellitus (E14) with 12\%. The majority of beneficiaries were male (71.7\%), associated with urban jobs (46.7\%) especially administrative posts, ranging from 50 to 64 years old (63\%).

Discussion The profile of workers who have requested benefits due to diabetes mellitus showed that the majority of beneficiaries were male adults, working in urban jobs ranging from 50-64 years old, mainly affected by Insulin-dependent diabetes mellitus disease. In addition, these beneficiaries can be more susceptible to workplace thermal conditions, stress and other issues inherent to the disease, such as hypo or hyperglycemia. These data should help in the implementation of strategies and measures to prevent the work disability caused by diabetes involving Brazilian workers and improve the worker's quality of life.

\section{ASSESSMENT OF CHILD LABOUR IN AGRICULTURE AMONG SYRIAN REFUGEES IN LEBANON}

RR Habib. Department of Environmental Health, American University of Beirut, Lebanon

\subsection{6/oemed-2018-ICOHabstracts.887}

Introduction The Syrian war, ongoing since 2011, has had numerous implications on Lebanon's precarious infrastructures and labour economy. Over 1 million Syrians have sought refuge in Lebanon, and with laws prohibiting working of displaced Syrian adults, many Syrian families and Lebanese employers have become dependent on working Syrian children particularly in the agricultural sector.

Methods This research study employs mixed methods, both quantitative and qualitative approaches. A household survey will be carried out with 1409 families in Syrian refugee communities located near agricultural areas in Lebanon to assess child labour practices among the displaced children and their families. Stakeholder focus group discussions will also be conducted, made up of members of the displaced community and a number of local and government institutions involved in the management of the refugees' livelihood. Data and trends from the qualitative and quantitative analysis will be triangulated to develop a holistic understanding of Syrian child labour in the Lebanese agricultural sector. Findings will be stratified by age, gender, refugee camp, and other variables.

Results The study will provide contextualised analysis of the nature and dynamics of the precarious involvement of Syrian children in the agricultural labour force, via focusing on both the living and working conditions of Syrian working children, as well as on the socioeconomic processes and environment in which children work. The study will also suggest recommendations for intervention at the field, family, community, and policy levels.

Discussion Enriched understanding of the underlying socioeconomic factors that drive refugee children to participate in the agricultural labour force will better guide the development of evidence-based interventions that support child education and address underlying issues of familial financial instability. This research can be used to inform labour policies and guidelines that will have positive, tangible impacts on the lives of displaced children and their families.

\section{EXCHANGE AND COOPERATION: OCCUPATIONAL HEALTH SURVEILLANCE IN THE BELT AND ROAD OF CHINA}

Q Hou, ZB Wang. Shanghai Institute of Occupational Disease for Chemical Industry, Shanghai, China

\subsection{6/oemed-2018-ICOHabstracts.888}

Background Occupational health and safety is highly related with economic activities in the country. As the economic globalisation grow and expand in China, such as the belt and road, this may result in high occupational health and safety services demand face new problems.

Objective To introduce the current situation of Occupational Health surveillance in China,compare Occupational health surveillance policy in different countries. To explore the problems and challenges that occupational health surveillance may face under the economic globalisation.

Findings Occupational health surveillance is an important part of occupational health and safety, which purpose is, from medical health examination and health related data collection, continuously monitoring the health status of workers, analysis of the relationship between occupation hazards and workers' health changes and contacts, in order to take intervention measures to protect workers health.Since 2002, China has legislateed, promulgated and revised 'People's Republic of China occupation disease prevention law', 'occupation health surveillance management regulation' 'occupation health surveillance technical standard', which has promoted occupation health surveillance work more legally and regularly. However, there are still some problems in occupational health surveillance, many large state-owned enterprises in China have established the occupational health and safety management system, but small and medium-sized enterprises generally lack occupational health care management. Occupational health monitoring is still at a low level. Through literature search, we collected the relevant laws and regulations of the United States, the United Kingdom, Australia, Canada, Finland, Japan, Southeast Asian countries and international organisations. There are great differences in occupational health surveillance management in different countries, Such as occupation health surveillance basic theory, management personnel and institution, occupation medical examination type and cycle, employer or enteprise responsibility.

Conclusions As the largest developing country, China has basically established a complete system of occupation health, occupation health surveillance work has achieved remarkable results. Economic globalisation provides a good opportunity for the management and research of occupational health care in China, we need more exchange and cooperation of occupation health and safety.

\section{4 SMOKE FREE CABS: ASSESSMENT OF IMPACT ON CAB DRIVERS AND COMMUTERS; AND TOBACCO CESSATION FOR CAB DRIVERS}

Gauravi A Mishra*, Sharmila A Pimple, Parishi Majmudar, Vasundhara V Kulkarni. Professor and Physician, Dept. of Preventive Oncology, Tata Memorial Hospital, Mumbai, India

\subsection{6/oemed-2018-ICOHabstracts.889}

Objectives Tobacco epidemic is one of the biggest public health threats, killing nearly seven million people annually. With implementation of smoke free public places legislation, 
cabs in India are smoke free. However, large majority of the cab drivers are addicted to tobacco.

The study objectives were to measure cab driver's knowledge and opinion about tobacco, understand pattern of tobacco usage, provide assistance in quitting tobacco, perform oral cancer screening, measure effectiveness of smoking ban in cabs and understand perceptions of cab drivers to ban.

Methods $400 \mathrm{cab}$ drivers in Mumbai were enrolled and interviewed. They were offered health education, oral cancer screening and tobacco cessation assistance at regular intervals over a year.

Results 64\% cab drivers used tobacco, mainly in smokeless forms (80\%). 94\% intended to quit, $66 \%$ had made previous quit attempts and 70\% expressed need of assistance for quitting tobacco. $62 \%$ had displayed a No Smoking sign in their $\mathrm{cab}$ and $75 \%$ expressed full compliance by passengers to the ban. $30 \%$ of cab drivers had oral precancerous lesions and one cab driver was diagnosed with invasive oral carcinoma. $32 \%$ of cab drivers had quit tobacco by the end of nine months and $36 \%$ cab drivers had reduced their tobacco consumption.

Conclusions Smoke free laws are important to reduce exposure of cab drivers to second hand smoke. However, many $\mathrm{cab}$ drivers are themselves addicted to tobacco and hence need assistance for quitting. We demonstrated the successful implementation of tobacco control and cessation program to support the Smoke Free Laws.

\section{IMPLEMENTING THE OCCUPATIONAL SAFETY AND HEALTH POLICY IN SENEGALESE COMPANIES: CASE STUDY OF THE NATIONAL WATER COMPANY OF SENEGAL (SONES)}

${ }^{1}$ Matam Dia Tall, ${ }^{2}$ Mourtadhoi Asnaya. 'Sones's Medical Centre, Dakar, Senegal; ${ }^{2}$ Vocational Training School, Dakar, Senegal

\subsection{6/oemed-2018-ICOHabstracts.890}

Introduction The implementation of the safety and health policy in Senegalese companies remains minimal or no existent. The objective is to study and evaluate the safety and health activities of SONES from 2011 to 2015.

Methodology and materials It is a five-year retrospective study (2011-2015) to assess the implementation of the safety and health policy of SONES. We included all existing health and safety initiatives. Our data sources were: the annual reports of the health and safety at work committee and the Medical Centre, questionnaires. Data were collected from the Excel file and analysed using the Epi info 3.5.1 software.

Results and discussion SONES has developed a health and safety policy and has an autonomous Medical Centre for 112 workers (96\% are permanent). Within the framework of the occupational hygiene and safety committee established since 2011, 79\% of the actions planned were carried out during the five years. There are stressors at SONES and they are linked to the workload, which is heavy and varied.

Conclusion The evaluation of occupational safety and health policy implemented by SONES from 2011 to 2015, has revealed the existence of occupational hazards mainly heavy load; psychosocial factors and ambient constraints. However, the management has taken several prevention control measures to improve working conditions.

\section{5 \\ OCCUPATIONAL DISEASE HAZARD FACTORS INVESTIGATION AND RISK ASSESSMENT IN ONE HOVERCRAFT MANUFACTURING ENTERPRISE}

Guang Zheng KePing Wang. Shanghai institute of Occupational Disease for Chemical Industry

\subsection{6/oemed-2018-ICOHabstracts.891}

Introduction Risk assessment can provide the technology measurement to decrease the accident. China has issued two national occupational health standard- 'Classification of occupational hazards at workplaces' (GBZ/T229-2010) and' Classification for hazards of occupational exposure to toxicant' (GBZ/T230-2010) in 2010. According to the toxicant exposure standard, calculating the hazards level, exposure to toxicant and labour intensity of workers can assess the exposure risk of workers. This study investigates and assesses the occupational disease hazard factor in the Hovercraft manufacturing enterprise.

Method To adopt the occupational health investigation method, detection and testing method and risk assessment method to measure and analyses the concentration or intensity of occupational hazards in workplace, and develop the qualitative and quantitative analysis according to the national occupational health standard- 'classification of occupational hazards at workplaces' and 'classification for hazards of occupational exposure to toxicant'.

Results On the basis of Chinese national standard 'Specifications of air sampling for hazardous substances monitoring in the workplace', concentration of ten occupational hazards factors which are Fibrous glass dust, Welding fume, Styrene, Acetone, Ozone, Carbon monoxide, Nitrogen dioxide, Sulfur dioxide, Epichlorohydrin, Manganese are detected under the national standard. The highest toxicant hazards index of Sulfur dioxide and Epichlorohydrin is 59, and the lowest toxicant hazards index of Nitrogen dioxide is 40 in the 10 occupational hazards of this factory.

Conclusion There are higher occupational hazards risk in glueinggluing post of Boat manufacturing. The hazard level of styrene and epichlorohydrin is highest in the 10 occupational hazards.

\section{EXPANSION OF OCCUPATIONAL HEALTH TO INCLUDE ENVIRONMENTAL AND COMMUNITY HEALTH: A PHILIPPINE EXPERIENCE}

Joselito L Gapas*. First Philippines Holdings Corporation, Pasig City, Metro Manila, Philippines

\subsection{6/oemed-2018-ICOHabstracts.892}

Introduction Occupational health $(\mathrm{OH})$ in Philippines private sector companies is changing, being driven by awareness that promotion and protection of worker's health is a good investment. Challenges include limited $\mathrm{OH}$ competency, limited regulatory compliance, and low appreciation of proactive and risk based approach. The First Philippine Holdings Corporation $(\mathrm{FPH})$ is involved in energy generation, real estate, construction, manufacturing, and health care. Since 2011, FPH began developing a risk-based $\mathrm{OH}$ management system. The Philippine Environmental Impact System (EIS) System requires environmentally critical projects to conduct an environmental and health Impact assessment including regular assessment risk assessment and impacts to workers and host communities. 